\title{
Neonatal Surgical Emergencies in Gabriel Touré Teaching Hospital in Bamako: Epidemiological and Clinical Aspects
}

\section{Dicko-Traoré $\mathrm{F}^{1,2}$, Diall H${ }^{1}$, Koné $\mathbf{I}^{1}$, Samaké $\mathrm{B}^{1}$, Coulibaly $\mathbf{0}^{1}$,

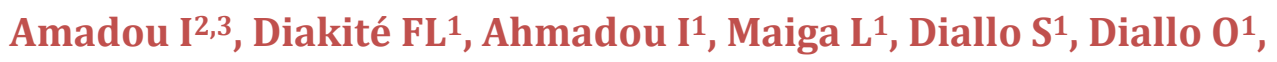 Nzonou E, Bocoum A1, Diallo A1, Diakité AA ${ }^{1,2}$, Coulibaly $Y^{2,3}$, Togo} $\mathrm{PA}^{2,3}$, Sylla $\mathbf{M}^{1,2}$

${ }^{1}$ Department of Pediatrics, CHU Gabriel Touré, Mali

${ }^{2}$ Faculty of Medecine and Odonto-stomatology, Mali

${ }^{3}$ Department of Surgery, CHU Gabriel Touré, Mali

\section{Research Article \\ Volume 4 Issue 1}

Received Date: January 07, 2019

Published Date: January 18, 2019

*Corresponding author: Fatoumata Dicko-Traoré, Department of Pediatrics, CHU Gabriel Touré, BP:1806 Bamako-Mali, Tel: 00223 66714593; Email: fatdickoped@gmail.com

\section{Abstract}

Neonatal surgical emergencies are common causes of neonatal morbidity and mortality. The aim of the study was to access epidemiological, clinical and prognostic characteristics of newborns hospitalized for surgical emergencies.

Material and Methods: We conducted a one-year prospective study from January 1 $1^{\text {st }}, 2016$ to December $31^{\text {st }}, 2016$ in the neonatology service in the Pediatric Department of Gabriel Touré Teaching Hospital in Bamako, the capital city of Mali. All neonates from 0 to 28 days hospitalized for a surgical emergency were included.

Results: One hundred and fourteen cases of surgical emergencies were recorded, i.e. $3 \%$ of hospitalizations. The average maternal age was 24 years old. Sex ratio was 1.1. The average consultation time was 7.5 days. In 55\% of cases, newborns were premature. The antenatal diagnosis was made in 7 patients. Congenital malformation pathology accounted for 92.98\% of ailments. Digestive diseases predominated with $72.9 \%$. These were mainly omphalocele (17.5\%), anorectal malformations (13.2\%), and laparochisis (12.3\%). Hirshprung's disease was found in two newborns (1.8\%). Surgery was performed in 59 neonates (51.8\%). The per and postoperative lethality was $55.26 \%$. The overall case fatality rate was 49.1\%. The most lethal pathology was laparoshisis (100\%). Factors associated with mortality were maternal insctruction level $(p=0.00)$, vaginal delivery $(p=0.01)$, and laparoschisis $(p=0.000)$.

Conclusion: A real policy by the health authorities to reduce mortality related to neonatal surgical pathologies is needed.

Keywords: Newborn; Surgical emergencies; Mortality 


\section{Pediatrics \& Neonatal Biology Open Access}

\section{Introduction}

Neonatal surgical emergencies are common causes of neonatal morbidity and mortality [1]. Neonatal surgical pathologies are abnormal structures or functions that manifest themselves from birth to the end of the first month of life and require urgent surgical treatment $[1,2]$. It is most often a surgical emergency involving the vital and / or functional prognosis. While in the industrialized countries, life expectancy has improved as a result of antenatal diagnosis, in developing countries there are several difficulties in managing it [2,3]. In Africa, they would motivate about $10 \%$ of surgical procedures in the various pediatric surgery departments [3,4]. Neonatal surgical emergencies accounted for $19.8 \%$ of admissions to the Pediatric Surgery Department of the University Hospital Center of Yopougon in Abidjan, Côte d'Ivoire [5] and $12.8 \%$ of those in the Pediatric Surgery Department of National Lamordè Hospital in Niamey, Niger [6]. In some settings, neonates are cared for in general surgery departments. This is the case in Bukavu in the Democratic Republic of Congo, where the surgical pathology of the newborn represents $1.31 \%$ of the surgical one [7]. In Bamako, Mali, the neonatology and pediatric surgery departments, the last level of national reference structures, provide synergistic care for neonatal surgical conditions. Until then, no study had examined the problem of surgical diseases of the newborn admitted to the neonatology service. The aim of the study was to access epidemiological and clinical characteristics of newborns hospitalized for surgical emergencies.

\section{Patients and Method}

We conducted a one-year prospective study from January 1st, 2016 to December 31 st, 2016 in the neonatology service in the Pediatric Department of Gabriel Touré Teaching Hospital in Bamako, the capital city of Mali. It provides care to newborn referred from the city of Bamako and its neighboring areas. The service receives all neonatal emergencies including surgical ones.

The management of newborns with surgical pathologies is multidisciplinary. Surgical management is provided by pediatric surgeons and pre- and postoperative surgery by neonatologists. All neonates from 0 to 28 days hospitalized for a surgical emergency were included. Non-life-threatening conditions that have been postponed to surgery as well as cardiac malformations have not been included. The parameters studied were: age, sex, origin, birth weight, consultation time, types of surgical pathology, consultation time, operating time, mortality, causes of death and factors associated with the death. The data were collected on a standardized survey form. The data capture and analysis were done on SPSS version 20. For the analysis of prognostic factors, the Chi-square and Fisher tests were used with a significance level of less than $5 \%$.

\section{Results}

During the study period, 3766 patients were hospitalized in the neonatology department. Among them,114 patients (3\%) presented surgical pathology. The average maternal age was 24 years old. Mothers were housewives and school dropouts $75 \%$ and $65.8 \%$ respectively. Primigravida and primiparous were respectively $62.3 \%$ and $34.2 \%$ of cases. Vaginal birth was the main mode of delivery (81.6\%). Sex ratio was 1.1 . Fifty-nine (59) newborns were admitted during the first 24 hours of life $(51.8 \%)$. The average consultation time was 7.5 days. The average birth weight was $3000 \mathrm{~g}$. In $55 \%$ of cases, newborns were premature. The antenatal diagnosis was made in 7 patients (6\%). The main sociodemographic characteristics and pre and per-natal antecedents are summarized in Table 1.

\begin{tabular}{|c|c|c|}
\hline Variable & $\begin{array}{c}\text { Frequency } \\
\text { (n=114) }\end{array}$ & Percent \\
\hline Maternal age & & \\
\hline 14-18 years old & 25 & 21.9 \\
\hline 31-47 years old & 17 & 15 \\
\hline $\begin{array}{c}\text { Level of education of } \\
\text { the mother }\end{array}$ & & \\
\hline Unschooled & 75 & 65.8 \\
\hline Schooled & 39 & 34.2 \\
\hline Gesture and parity & & \\
\hline Primigravida & 71 & 62.3 \\
\hline Primipare & 39 & 34.2 \\
\hline Delivery route & & \\
\hline Vaginal & 93 & 81.6 \\
\hline Caesarean section & 21 & 18.4 \\
\hline Birth weight & & \\
\hline Hypotrophe & 48 & 42 \\
\hline Eutrophic & 61 & 53.5 \\
\hline Sex & & \\
\hline Male & 62 & $54.00 \%$ \\
\hline Female & 52 & $46.00 \%$ \\
\hline
\end{tabular}

Table 1: Socio-demographic characteristics and pre- and per-natal antecedents. 


\section{Pediatrics \& Neonatal Biology Open Access}

Congenital malformation pathology accounted for $92.98 \%$ of ailments. Digestive diseases predominated with $72.9 \%$. These were mainly omphalocele $(17.5 \%)$, anorectal malformations (13.2\%), and laparochisis (12.3\%). Hirshprung's disease was found in two newborns (1.8\%). A case of hypertrophic stenosis of the pylorus and a case of atresia of the esophagus have been observed. Bowel obstruction motivated hospitalization in $2.6 \%$ of cases. Peritonitis was found in the same proportions $(2.6 \%)$. Ulcerative necrotizing enterocolitis was diagnosed in two neonates (1.8\%). Myelomeningocele accounted for $13.2 \%$ of ailments. Sacrococcygeal teratoma was found in two neonates. Encephalocele was found in $1.8 \%$ of newborns. Abnormalities of the urogenital tract accounted for $0.9 \%$ of surgical pathologies. The main pathologies found are summarized in Table 2.

\begin{tabular}{|c|c|c|}
\hline Variable & $\begin{array}{c}\text { Frequency } \\
\text { (n=114) }\end{array}$ & Percent \\
\hline Digestive diseases & & \\
\hline Omphalocele & 20 & 17.5 \\
\hline Gastroschisis & 14 & 12.3 \\
\hline Imperforate anal & 15 & 13.2 \\
\hline Atresia of the esophagus & 1 & 0.9 \\
\hline Bowel obstruction & 3 & 2.6 \\
\hline Peritonitis & 3 & 2.6 \\
\hline $\begin{array}{c}\text { Ulcerative necrotizing } \\
\text { entérocolitis }\end{array}$ & 2 & 1.8 \\
\hline $\begin{array}{c}\text { Neurological } \\
\text { pathologies }\end{array}$ & 15 & 13.2 \\
\hline Myelomeningocele & 6 & 5.3 \\
\hline Hydrocephalus & 2 & 1.8 \\
\hline Encephalocele & 2 & 1.8 \\
\hline Sacrococcygeal teratoma & 1 & 0.9 \\
\hline Other conditions & 5 & 4.4 \\
\hline $\begin{array}{c}\text { Valve of the posterior } \\
\text { urethra }\end{array}$ & & \\
\hline Cleft lip and palate & & \\
\hline
\end{tabular}

Table 2: Main surgical pathologies.

Surgery was performed in 59 neonates (51.8\%). Sixtyseven-point three percent $(67.3 \%)$ of the digestive disorders were operated on, followed by abnormalities of the vertebral column (29.1\%) and those of the head (9.1\%). The intervention was made within 24 hours in 34 newborns or $58.6 \%$ of cases. The per and postoperative lethality was $55.26 \%$. The overall case fatality rate was
49.1\%. The most lethal pathology was laparoschisis $(100 \%)$. Factors associated with mortality were maternal instruction level $(p=0.00)$, vaginal delivery $(p=0.01)$, and laparoschisis $(p=0.000)$. Table 3 presents factors associated with mortality.

\begin{tabular}{|c|c|c|c|}
\hline \multirow{2}{*}{ Studied factor } & \multicolumn{2}{|c|}{ Frequency } & \multirow{2}{*}{ P-value } \\
\cline { 2 - 3 } Sex & Death & Live & \\
\hline Male & & & \\
\hline Female & 31 & 32 & 0.98 \\
\hline Schooling of the mother & & & \\
\hline Yes & 25 & 26 & \\
\hline No & 31 & 44 & $\mathbf{0 . 0 2}$ \\
\hline Delivery route & & & \\
\hline Low way & 40 & 53 & $\mathbf{0 . 0 1}$ \\
\hline Caesarean section & 16 & 5 & \\
\hline Low birth weight & & & \\
\hline Yes & 24 & 24 & 0.87 \\
\hline No & 32 & 34 & \\
\hline Type of pathology & & & \\
\hline Gastroschisis & 14 & 0 & $\mathbf{0}$ \\
\hline Omphalocele & 8 & 12 & \\
\hline Imperforate anal & 2 & 13 & \\
\hline Myelomeningocèle & 3 & 12 & \\
\hline
\end{tabular}

Table 3: Analysis of factors associated with mortality.

\section{Discussion}

Our study included all neonates from 0 to 28 days hospitalized for surgical pathology in the neonatal department during the study period. The frequency of surgical pathologies in the department was $3 \%$. This frequency probably does not reflect in the population. Indeed, in general, with visible malformative pathologies, the use of conventional care is not systematic and some of them are unknown at birth. Our frequency is close to that of Youl H [8] in Burkina Faso and Yadav P et al. [9] in Egypt who found $2.9 \%$ and $2.8 \%$ respectively. In other African series, neonatal surgical pathology accounted for $9.7 \%$ to $61 \%$ of admissions to pediatric surgery $[5,10]$. Studies in Africa [7,11-13] and Indian and British series [14-17] had annual incidences higher than ours ranging respectively from 11 to 25 and 60 to 301 new- born each year. The demographic characteristics of the populations and the specificities of the pediatric surgery services that cover them vary and determine the hospital impact [6]. In 


\section{Pediatrics \& Neonatal Biology Open Access}

our study, male newborns are the most affected. This predominance is also found in the study of Kokoé [Error! Reference source not found.] in Côte d'Ivoire and by other authors [10,12,19-21]. By contrast, in the Youl $\mathrm{H}$ series [8] in Burkina Faso, the female sex was predominant. There is no clear consensus regarding the predominance of a gender.

Although more than half of the newborns were admitted before the first 24 hours of life, the average consultation time in our study was 7.5 days. The delay in referral and late recourse to care are also mentioned by Yadav $P$ [9] in Egypt and Youl $H$ [8]. Congenital pathologies are the main neonatal surgical emergencies. They represented $92.98 \%$ in our series and $57 \%$ in the study of Omid AAM et al. [8].

Congenital surgical conditions should be prenatal diagnosed so that delivery takes place in a specialized resuscitation and neonatal surgery center [3]. Early endovaginal ultrasound examination, between the 12th and 14th week of amenorrhea, allows to detect the severe pathology of the fetus, such as abnormalities of the nervous system and the anterior abdominal wall [22]. In the third trimester, the ultrasound allows to specify the vitality of the digestive loops for a laparoschisis and the size and the contents of an omphalocele [22]. Antenatal diagnosis remains a handicap in developing countries. In our study, it could be performed in 7 newborns (6.1\%). In some studies, such as Ndour O [12] and Ralahy MF [23], no antenatal diagnosis has been made. The development of antenatal diagnosis has led to a reduction in the time taken to treat omphaloceles in Western countries, the United States and Europe [2].

In these countries, it is currently a benign pathology with a survival rate of $97 \%$ [2]. The pathologies of the digestive tract are the main neonatal surgical emergencies. In our series they accounted for $72.9 \%$ of cases. Their frequency ranged from $41.8 \%$ to $82 \%$ in most studies $[5,11,13,21,23,24]$. The digestive pathologies led to high mortality, linked to the difficulties of neonatal resuscitation and anesthesia due to the lack of qualified personnel in particularly neonatal pediatric anesthesia $[3,4]$. The neonates who underwent surgery were 59 out of 114 or $51.8 \%$ and the operative time was less than 24 hours for 34 cases or $58.6 \%$. In the Ndour 0 et al study, the mean operative time was 4 hours with extremes ranging from 2 hours to 7 days [12]. All our patients could not benefit from the surgery. This was due to the difficulties related to the delay of diagnosis and the limited financial means of the parents in the absence of a subsidy system or free support for emergencies in general.

In our study, the death rate was $49.1 \%$, the main factors associated with mortality were maternal instruction level $(p=0.00)$, vaginal delivery $(p=0.01)$, and laparoschisis $(p$ $=0.000$ ). Our case-fatality rate is lower than that of Ndour $O$ in Senegal [12] and Hounnou GM in Benin [19], which found respectively $68 \%$ and $50.6 \%$. All these authors justify the high mortality rate by: the fragility of the newborns, the diagnosis which is not made during the prenatal period, the absence of a specific neonatal resuscitation unit, the delay of consultation, the fact that the newborn is seen while it already presents some complications, the supply of drugs which is left to the sole responsibility of the parents and a mode of evacuation of the defective new-borns. These facts meet exactly the reality of home. The morbidity and mortality factors identified in various studies were: births at home or in rural health facilities, prematurity and low birth weight, damage to the digestive system, unsafe transportation, problems nutritional complications, anesthetic complications and the presence of multiple congenital anomalies [13,16,24]. For Ouedraogo I et al, prematurity, the existence of associated malformations and low birth weight are risk factors for mortality [25]. In the Ndour 0 et al study, $53 \%$ of the newborns who died had a low birth weight [12]. Hounnou GM [19] have made the same observation and agree that low birth weight is a factor of poor prognosis. According to Osifo OD, 1/3 of newborns with a malformation are premature [13].

The management of neonates with surgical pathologies must be multidisciplinary. In the West neonatal mortality has significantly decreased thanks to the progress of resuscitation and parenteral nutrition $[3,4]$. Advances in diagnostic techniques and perioperative care have greatly improved the therapeutic outcomes of neonatal surgery. Nevertheless, there are disparities in the results of neonatal surgery between high-income countries and those with average income and low income [2]. The difficulties of neonatal resuscitation and the limits of anesthesia of premature infants were responsible for 33\% of deaths [2]. In Nigeria, Amen EA et al were able to achieve a reduction in the neonatal mortality rate by improving the technical plateau $[13,26]$.

\section{Conclusion}

As in most countries in Africa, surgical emergencies place a heavy strain on newborn survival. Indeed, the lethality that is attributable to it remains very high. A real policy by the health authorities to reduce mortality related to neonatal surgical pathologies is needed. The 


\section{Pediatrics \& Neonatal Biology Open Access}

latter should promote prenatal diagnosis, the training of qualified personnel, the improvement of the technical platform and the accessibility of the populations to care.

\section{References}

1. WHO (2015) Birth defects surveillance training: facilitator's guide. World Health Organization pp: 1162.

2. Taguchi T, Nagata K, Kinoshita Y, Esumi G (2014) Progress in and outcomes of neonatal surgery over the past 50 years. Nihon Geka Gakkai Zasshi 115(6): 306-311.

3. Ekenze SO, Ajuzieogu OV, Nwomeh BC (2016) Challenges of management and outcome of neonatal surgery in Africa: a systematic review. Pediatr Surg Int 32(3): 291-299.

4. Chirdan LB, Ngiloi PJ, Elhaby EA (2012) Neonatal surgery in Africa. Semin Pediatr Surg 21(2): 151-159.

5. Mieret JC, Kouamé Yapo GS, Yaokreh JB, Dieth AG (2014) Pronostic des pathologies chirurgicales néonatales au CHU de Yopougon. Rev Int Sc Med 16: 126-129

6. Omid AAM, Hellé M, Habou O, Chérif Maiguizo AK, Habarchi H (2017) Les pathologies chirurgicales néonatales à l'hôpital national de Lamordé de Niamey: Aspects diagnostiques, thérapeutiques et pronostiques. European Scientific Journal 13(24): 1857-7431

7. Fabrice CG, Kabakuli AN, Ndechu AB (2016) Neonatal surgical emergencies at the Bukavu Provincial General Reference Hospital in Democratic Republic of Congo. Pan Afr Med J 24: 219.

8. Youl H (2014) Congenital malformations recognizable at birth in neonates in the pediatric department of the Souro Sanou University Hospital Center. Medical Thesis $n^{\circ} 225$ pp: 91.

9. Yadav P, Arpan M, Raina VK (2015) Neonatal Surgical Emergencies in a Tertiary Care Center. Journal of Surgery 1(5): 5-9.

10. Badrinath R, Kakembo N, Kissa P, Langer M, Ozgediz $D$, et al. (2014) Outcomes and unmet need for neonatal surgery in a ressouce limited environment: Estimates of global health disparities from Kampala Ouganda. J Ped Surg 49(12): 1825-1830.
11. Sowande OA, Ogundoyin 00, Adejuyigbe O (2007) Pattern and factors affecting management outcome of neonatal emergency surgery in Ile-lfe, Nigeria. Surg Pract 11(2): 71-75.

12. Ndour O, Faye FA, Alumeti D, Gueye K, Amadou I, et al. (2009) Risk factors for Neonatal Mortality Factors at the Paediatric Surgeon Service in Aristide Le Dantec University Hospital in Dakar. Mali Medical 24(1): 3338.

13. Osifo OD, Oriaifo IA (2008) Factors affecting the management and outcome of neonatal surgery in Benin City, Nigeria. Eur J Pediatr Surg 18(2): 107-110.

14. Narasimhan KL, Vivay B (2005) Priorities in development of neonatal surgery in India. Indian pediatrics 42(1): 82-83.

15. Burge DM, Drewett M (2012) Workload and costs associated with providing a neonatal surgery service. Arch Dis Child Fetal Neonatal 97(3): 179-181.

16. Nandi B, Mungougo C, Lakhoo K (2008) A comparison of neonatal surgical admission between two linked surgical departments in Africa and Europa. Pediatr Surg Int 24(8): 939-942.

17. Bhatnagar SN, Sarin YK (2012) Current trends in neonatal surgery in India. J Neonat Surg 1(2): 18-21.

18. Kokoé MGA, Kouassi DASL, Aké YL, Kouao JP, Boni R, et al. (2016) Les urgences chirurgicales néonatales dans le service de chirurgie pédiatrique du CHU de Cocody. Rev Int Sc Med 18(2): 161-164.

19. Hounnou GM, Koura A, D'Almeïda MES, Hounkpe VO, Ayivi B, et al. (2006) Neonatal intestinal obstructions in the national University Teaching Hospital of Cotonou: epidemiological, clinical and therapeutic aspects. Clin Mother Child Health 3(1): 457-464.

20. Catre D, Lopes MF, Madrigal A, Oliveiros B, Viana JS, et al. (2013) Early mortality after neonatal surgery analysis of risk factors in an optimized health care system for the surgical newborn. Rev Bras Epidemiol 16(4): 945-952.

21. Awad RA, Karasani SH (2014) Pattern of Neonatal Surgical Presentation and Outcome in Sinnar Hospital (2013-2014). Global Journal of Medical Research 14: 17-22. 


\section{Pediatrics \& Neonatal Biology Open Access}

22. Saldarriaga-Gil W, Ruiz-Murcia FA, Fandino-Losada A, Cruz-Perea ME, Isaza de Lourido C (2014) Evaluation of prenatal diagnosis of congenital anomalies diagnosable by prenatal ultrasound in patients in neonatal intensive care units of Cali, Colombia. Colomb Med (Cali) 45(1): 32-38.

23. Ralahy MF, Rakotoarivony ST, Rakotovao MA, Hunald FA, Rabenasolo M, et al. (2010) The neonatal mortality in the emergency unit of the JRA university teaching hospital in Antananarivo Madagascar. Revue d'anesthésie-réanimation et de médecine d'urgence 1(2): 15-17.
24. Ugwu RO, Okoro PE (2013) Pattern outcome and challenges of neonatal surgical cases in a tertiary teaching hospital. Afr J Pediatr Surg 10(3): 226-230.

25. Ouédraogo I, Kaboré R, Napon MA, Ouédraogo F, Ouangré E, et al. (2015) Epidemiology of neonatal surgical emergencies in Ouagadougou. Arch Pédiatr 22(2): 130-134.

26. Ameh EA, Justinia Seyi-Olajide 0, Tunde ST (2015) Neonatal surgical care: a review of the burden, progress and challenges in sub-Sahara Africa. Peadiatr Int Child Health 35(3): 243-251. 